\title{
An integrated framework for design, management and operation of reconfigurable assembly systems
}

\author{
Massimo Manzini ${ }^{\mathrm{a}, *}$, Johannes Unglert ${ }^{\mathrm{b}}$, Dávid Gyulai ${ }^{\mathrm{c}, \mathrm{d}}$, Marcello Colledani ${ }^{\mathrm{a}}$, Juan Manuel Jauregui Becker ${ }^{\mathrm{b}}$, \\ László Monostoric,d, Marcello Urgo ${ }^{\mathrm{a}}$ \\ ${ }^{a}$ Politecnico di Milano, Department of Mechanical Engineering, Milan, Italy \\ ${ }^{b}$ University of Twente, Department of Design, Production and Management, Enschede, The Netherlands \\ ${ }^{c}$ Fraunhofer Project Center PMI, Institute for Computer Science and Control, Hungarian Academy of Sciences, Budapest, Hungary \\ ${ }^{d}$ Budapest University of Technology and Economics, Department of Manufacturing Science and Engineering, Budapest, Hungary
}

\begin{abstract}
Manufacturing has to cope with continuously increasing variety of products, reduction of volumes and shortening of products' life cycle, in particular in the automotive sector under the pressure of continuously adapting production targets in relation to the frequent introduction of new model variants, materials and assembly technologies. In this context, the design of assembly systems and their co-evolution is of paramount importance for the company competitiveness. In this paper, we propose an approach for the design and reconfiguration of modular assembly systems through the integration of different configuration tools addressing the configuration of the multi-cellular system, the optimization of the layout, the planning of reconfiguration actions as well as production planning. Integrating these tools and iterating through the resulting workflow allows to consider the outcomes and dependencies of alternative decision sequences holistically with the objective of an effective and efficient approach to production system design and management. The viability of the approach is demonstrated through the application to an automotive case study.
\end{abstract}

Keywords: reconfiguration, manufacturing, design, layout, assembly, uncertain market

\section{Introduction and motivation}

Throughout the last decade, manufacturing industry has been confronted with an increasing variety of products and the consequent production volumes reduction, together with the continuous shortening of products' life cycle (ElMaraghy et al., 2013). In this context, the design of manufacturing systems becomes a complex task that entails manufacturing strategy decisions, has longterm impact and involves a major commitment of financial resources (Terkaj et al., 2009a). Hence, manufacturing systems must be able to smoothly and rapidly adapt to the fast evolving market dynamics. Different paradigms have been proposed to cope with these requirements, i.e., flexibility and reconfigurability (Koren et al., 1999; ElMaraghy, 2005), exploiting specific technological enablers like modularity and changeability (Wiendahl et al., 2007). Moreover, the concept of co-evolution of products, processes and production systems has been identified as a key factor in companies to

\footnotetext{
${ }^{*}$ Corresponding author
}

manage strategically and operationally the propagation of engineering changes and to gain competitive advantage from the resulting market and regulatory dynamics (Tolio et al., 2010).

In this paper, we focus the attention on tier-one automotive suppliers of car-body assemblies. Original Equipment Manufacturers (OEMs) typically rely on this class of suppliers to produce spare parts for the aftermarket. Nevertheless, as $O E M \mathrm{~s}$ are moving towards a growing variety of models, suppliers are often involved in the production of parts during the ramp-up of new models, as well as in complementing the OEMs production capacity for low volume car model niches or to help managing demand peaks. Besides the variability of demand present in these product segments, the automotive industry is also experiencing a continuous technological evolution, with joining technologies being continuously upgraded and the increase of the overall complexity and requirements for the assembly process. All these factors have to be considered in the manufacturing strategies applied by the suppliers.

In addition, suppliers have very limited degrees of 
freedom. OEMs provide them the design of the products, the associated assembly technologies and processes and, in many cases, also, the specifications for the equipment that must be used. Hence, the only strategic factors the supplier can exploit are the design and management of their production systems to quickly adapt to the $O E M$ s requirements. At the same time, these systems need to evolve in the medium and long term, to cope with the evolution of products and technologies and guarantee the company's competitiveness.

In this perspective, we propose an integrated design approach for assembly lines. The approach entails four tools: (i) the definition of the system's architecture and multi-cell configuration, (ii) the selection of the cell's detailed layout configuration and assembly process' options, (iii) the production planning and (iv) the reconfiguration steps that have to be taken between the time periods. The four tools can be used in a sequence, to design an assembly system and the associated managing policies. Using the tools in the sequence of the workflow allows to incrementally increase the level of details and gain additional knowledge about the system. Moreover, feedback loops are implemented between the tools, to improve the design or manage possible infeasibility. The integration of the decision-support tools aims at providing a robust solution able to cope with the co-evolution of the system together with the products and the production technologies. In this fashion, the configuration, layout and reconfiguration of the system consider long-term decisions, while the planning of production and setups addresses the short-term horizon. The paper is organized as follows: Section 2 provides a state-of-the-art for the different research areas related to the integrated approach, Section 3 addresses the overall formulation and notation, Section 4 provides the structure of the integrated design approach while in Section 5 a detailed description of the tools and functionalities of the approach is presented. Section 6 illustrates the application to an industrial case in the automotive industry while Section 7 provides a summary of the approach and future research directions.

\section{Design and management frameworks: state-of- the-art}

The approach we present in this paper is based on the integration of different tools supporting a wide range of decisions affecting the production system throughout its whole life cycle. Grounding on the modular implementation of the proposed approach, the state-of-the-art analysis considers literature, dealing with system con- figuration, layout, management and integration of these aspects.

Using cellular manufacturing systems as means to achieve manufacturing flexibility has been a subject for research already for a long time (Selim et al. (1998)). Even though advances are documented in more recent publications such as Papaioannou and Wilson (2010), a number of challenges in the field has remained until today. One aspect that has been identified as vital for successfully applying the cellular concept is the consideration of is dynamics in design models, as described by Goldengorin et al. (2010). The authors conclude that, since the product mix changes over time, also the cell's layout must be adjusted from period to period to obtain systems, which are robust with regard to a changing product mix, or dynamic, with regard to realizing smooth changes of the system's structure.

The general configuration problem for assembly systems has been widely studied in literature. In Guschinskaya et al. (2008), authors consider the configuration problem for assembly systems without buffers by using a heuristic multi-step approach. They face the problem of grouping operations in several stations and minimizing the total equipment cost. They propose partitioning the layout design process into several steps and introducing technology constraints and precedence relations sequentially. All manufacturing operations are considered with a fixed assignment of the tools to spindles and without taking into account alternative machining processes. The extension of this work is presented in Makssoud et al. (2014), where also reconfiguration actions are considered. In both cases, the volumes to be produced and also the processing times are treated as deterministic parameters. A similar configuration problem is faced in Guschinskaya et al. (2011) by using a three-step genetic approach. A different approach for the assembly line design and balancing is proposed in Oesterle and Amodeo (2014), exploiting a heuristic algorithm. Demand uncertainty is faced in Papakostas et al. (2014) by considering the maximization of the ratio between throughput and costs. Also in this case, processing times are considered deterministic and reconfiguration actions are not possible. Another stream of research is represented by Michalos et al. (2015), where a multi-criteria design approach is proposed consisting of two phases: first, a set of equipment components is selected for the system and, subsequently, arranged to form the assembly line configuration using an optimization algorithm. Similarly, however focusing on the total cost of ownership, Heilala et al. (2006) present an approach, which combines design and simulation of modular assembly systems. 
Hu et al. (2011a) and Koren and Shpitalni (2010) suggest to integrate the layout of production systems with production planning to match the system structure with the customers' demands. Nevertheless, they argue that this topic so far received little attention by researchers. In Li et al. (2011), authors argue that the throughput of the system is usually determined by considering the bottleneck process only, however, without considering the applied production sequence. Another lack described in literature is the consideration of setups and changeovers during the design phase of the line: Nazarian et al. (2010), Boysen et al. (2007) and Battini et al. (2011) expose that the link with production planning and the resulting actual batch sizes and changeovers appears to be rather loose.

An integrated methodology focusing on the automotive assembly process is presented by Ceglarek et al. (2015), where the authors consider the configuration of a remote laser welding assembly line together with the production process and task sequencing. These approaches focus on design and high level performance evaluation, without taking into account the reconfiguration of the system. One approach to design reconfigurable systems is described by Matta et al. (2007). Their approach starts with estimating the system's ramp-up performances, considering the reconfiguration option to increase or decrease the system's capacity. In addition, the authors generate a robust solution by applying a Markov decision process to consider multiple time periods. An approach that takes into account the design of a multi-product flexible transfer lines and its reconfiguration is presented by Tolio and Urgo (2013). In particular, the configuration phase consists in assigning operations and pieces of equipment to selected stations, while during the reconfiguration phase, the pieces of equipment are rearranged to match the changed requirements. In relation to integrated approaches covering all the phases mentioned in Section 4, an interesting work is presented by $\mathrm{Hu}$ et al. (2011b), where multiple approaches to design assembly systems are reviewed and summarized, taking into account reconfigurability, flexibility and co-evolution aspects.

The literature described above shows a representative part of the vast number of contributions to support assembly system configuration, reconfiguration and management. The gaps highlighted will be addressed by the approach described in this paper. Nevertheless, the main gap we have identified lies elsewhere: While the approaches and techniques for solving the problems of system configuration, reconfiguration and production planning are mostly discussed apart from each other, the dependencies between the results of these special- ized approaches are often not considered in the generated solutions. In contrast to this, we propose to integrate specialized approaches to support the initial system configuration, layout optimization, reconfiguration planning, production planning and simulation. The objective of our approach is to consider the dependencies and mutual effects by allowing the decision-makers to efficiently iterate through the configuration steps to ensure the feasibility of solutions and achieve compatible results for all the sub-problems.

\section{Reconfigurable assembly line design problem for- mulation}

The overall configuration problem is partitioned into three sub-problems. Firstly, a suitable multi-cell system architecture must be identified. This implies to decide about the number of cells and the assignment of products and the sequence of their production steps, resulting in the routing of products between the cells. Also in this step, the modular production resources used for assembly are selected and assigned to the cells. Secondly, the selected equipment components must be arranged into the assembly cell architecture to define a specific layout and, consequently, the task sequencing, in which the detailed use of alternative assembly equipment is considered. Thirdly, the planning of production needs to be considered to check whether the requirements of the $O E M$ can be guaranteed. Eventually, the reconfiguration problem is considered on a long time horizon, taking into account the reconfiguration actions between the time periods.

In more details, we consider a production problem in terms of a set of products $P$ to be assembled making use of a set of equipment groups called Functional Assembly Groups (FAGs). A FAG consists of one or more pieces of equipment, together with the tools and fixtures needed to accomplish a given set of assembly operations. Specifically, a $F A G$ characterizes a set of hardware components required for a given class of assembly operations (e.g. resistance spot welding, gluing, hemming). The processing information for the product $p \in P$ is provided in terms of technological parameters (e.g. number of weld joints, hemming or gluing length) and the associated unitary processing times. Additional non-operational data related to a $F A G$ (e.g. the floor space requirements, the investment costs and depreciation period) is taken into account. Given the pieces of equipment available, the set of assembling operations associated to a $F A G$ can be executed in different alternative ways. These alternative options - called execution 


\begin{tabular}{|c|c|}
\hline \multicolumn{2}{|r|}{ Sets } \\
\hline $\bar{T}$ & set of time periods \\
\hline$P$ & set of products \\
\hline$J$ & set of modules \\
\hline$C$ & set of working cells \\
\hline$K$ & set of execution modalities considered \\
\hline$\Omega$ & set of scenarios \\
\hline$Z$ & set of different configurations generated \\
\hline \multicolumn{2}{|r|}{ Variables } \\
\hline$x_{p t c}$ & volume of product $p$ produced in period $t$ in cell $c$ \\
\hline$y_{p t c}$ & indicator: if cell $c$ is producing $p$ in period $t$ \\
\hline$r_{p t c}$ & setup performed in cell $c$ for product $p$ in period $t$ \\
\hline$s_{p t}$ & amount of product $p$ delivered in period $t$ \\
\hline$i_{p t}$ & inventory level of product $p$ in period $t$ \\
\hline$b_{p t}$ & planned backlogs from product $p$ in period $t$ \\
\hline$h_{c t}$ & headcount of operators at cell $c$ in period $t$ \\
\hline$\underline{z_{c t}}$ & configuration chosen for cell $c$ and time period $t$ \\
\hline \multicolumn{2}{|r|}{ Parameters } \\
\hline$\overline{t_{p}^{m}}$ & machine cycle time of product $p$ \\
\hline$t_{p}^{h}$ & manual cycle time of product $p$ \\
\hline$t^{s}$ & duration of a reconfiguration for product $p$ \\
\hline$t^{p}$ & length of a time period \\
\hline$d_{p t}$ & volume of product $p$ to be delivered in period $t$ \\
\hline$a_{p c}$ & indicator: if product $p$ can be assembled in cell $c$ \\
\hline$n_{j}$ & amount of modules from type $j$ \\
\hline$r_{j p}$ & number of modules $j$ required by product $p$ \\
\hline$c^{b}$ & cost of backlog per product and period \\
\hline$c^{s}$ & cost of inventory holding per product per period \\
\hline$c^{h}$ & cost of an operator per period \\
\hline$q$ & depreciation rate \\
\hline cost $_{o p}$ & hourly operative cost \\
\hline $\operatorname{cost}_{\text {inv }}(j)$ & unitary purchasing cost \\
\hline$T C$ & unitary tool cost \\
\hline$S_{p}(\omega)$ & set of production processes for $p \in p(\omega)$ \\
\hline$d_{p}(\omega)$ & demand for each $p \in p(\omega)$ \\
\hline$l_{p}(\omega)$ & batch size for each $p \in p(\omega)$ \\
\hline
\end{tabular}

Table 1: Notation for data and variables.

modalities - are provided in the set $K$ in terms of the associated task sequencing and processing times. Further details on execution modalities and the associated technological characteristics are provided in Section 5.2.

FAGs are modular devices, easily organizable in a layout and — from a design point of view — they act as a technological enabler for the changeability of the assembly layout. The FAGs can be managed in two different ways when considered in relation to two different time horizons: in the short term, the available tools can be retooled to cope with different parts to be assembled, which is referred to as changeover. On a longer time horizon, however, there is an opportunity to modify the set of available $F A G$ s, i.e., acquiring new ones or dismissing available ones; we refer to this as reconfiguration as it entails the modification of the available equipment. Handling and transportation devices (e.g., 7-axis robot) move the parts within the assembly line; these devices can be shared by various FAGs and are required for the operation of every cell. Finally, dedicated stations are considered to enter and exit the assembly cell (I/O stations); these stations are typically operated manually.

To limit the set of alternative layouts, we consider a general architecture for each assembly cell (Figure 1). It is composed of a 7-axis robot with different stations (both $I / O$ and $F A G$ s) arranged around the central rail. The whole cell is protected by security fences and automatically managed by a control unit.

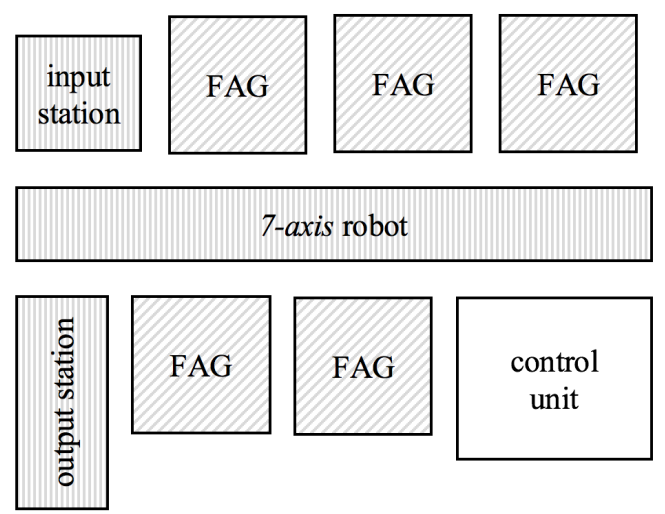

Figure 1: Schematic working cell architecture representation. Each equipment type is represented with a different pattern.

In formal terms, a layout configuration is represented by a variable $z=(E, F, V)$ where $E$ defines the type of FAGs and their position in the layout (Figure 1); $F$ defines the set of tools that must be made available for the FAGs to process the different parts and $V$ defines a proper execution modality for each assembly activity. As described in Section 1, the proposed approach also aims at providing a reconfiguration strategy to cope with the evolution of the production requirements. To formalize this evolution, a probabilistic scenario model is used, to structure the uncertainty associated to future events. A stochastic scenario tree is defined, consisting of a set of nodes $\Omega$ over a set of time periods $T$. Each node $\omega \in \Omega$ in the tree is associated to a set of production requirements, i.e., the products $P(\omega)$ to be produced and the associated volumes $d_{p}(\omega)$, the average lot sizes $l_{p}(\omega)$ and the assembly processes $S_{p}(\omega)$. An occurrence probability $\pi(\omega)$ is assigned to each node. A path starting from the root of the tree and ending in a leaf represents a specific evolution scenario with its occurrence probability. 
Considering the overall time horizon of the scenario tree, a selection of the multi-cell system architecture can be performed, to identify the preferred ones and to prune the infeasible or dominated options. Hence, grounding on the candidate architecture, for each node $\omega$ in the scenario tree, a specific cell configuration $z_{c t}$ is provided (where $c$ represents the cell under study and $t$ is the time period in which we are operating), able to cope with the requirements in node $P(\omega)$. Within the time period associated to this node, the tools available are rearranged every time a different part must be assembled according to the production management strategy. The operation paradigm is the multi-product assembly cell, where the production of batches of parts needs to match the customer demand and the associated delivery dates. When moving from one node to another, the cell configuration $z$ can change, thus requiring a reconfiguration action. The overall design and reconfiguration approach of a cell aims at defining the best for each cell over the whole scenario tree considering the associated cost (investment, reconfiguration, operational, etc.).

In general terms, the approach addresses the coevolution (Tolio et al., 2010) of the production cell together with the products and the processes, to provide a robust design and management approach (Terkaj et al., 2009b). In our terminology, robustness is defined as the capability of guaranteeing the required performance independently of external disturbances such as the evolution of the production requirements, and/or internal ones, such as machine failures.

\section{Assembly system design and management frame- work}

The proposed integrated approach is organized according to the workflow in Figure 2. It is based on four software tools that make use of a common data structure and act in an integrated way: the Assembly System Configuration tool, the Assembly Cell Configuration tool, the Production Planning and Simulation tool and the Reconfiguration Planning tool. Starting from the set of production requirements, the Assembly System Configuration tool is used to explore the design space, compare different system configurations and to identify the most promising ones. At this stage, the tool synthesizes system configurations that are based on various ways of assigning the available equipment and products to one or multiple cells, allowing for a high-level performance analysis. The aim of the tool is - within the generated architectures - to identify advantageous system configurations. These high-level designs are then handled by the Assembly Cell Configuration tool. This tool
— grounding on the system-wide configuration- goes into the layout configuration process by arranging the equipment into a cell layout, selecting the proper task sequencing and, finally, evaluating the dynamic performances of the proposed solution. The latter can be further evaluated from the management point of view by the Production Planning and Simulation tool. Taking into consideration detailed orders and delivery dates, this tool sequences the production batches in the assembly line over a short-term planning horizon, also taking into consideration the availability of raw materials and personnel. The performances of the system are evaluated through a DES model, thus considering the system in greater detail. The three tools are designed to work in an integrated way, i.e., feedbacks between different design steps are implemented, with the aim of improving the configuration design and managing possible infeasibility. Finally, the Reconfiguration Planning tool addresses the evolution of the assembly cell according to the evolution of the production requests modeled through scenario tree, like the bottom right of Figure 2 . The aim is in terms to provide a robust design for the assembly line, consisting of an initial configuration and a set of reconfiguration steps to match the uncertain market evolution described by the paths in the scenario tree. The whole approach grounds on a common description of the production problem to be addressed, whose notation is reported in Table 1.

\section{Description of individual tools}

Each tool contributes with specific capabilities to the objectives of the support framework. The pecularities of the approaches are described in the following sections.

\subsection{The Assembly System Configuration tool}

A few knowledge-based systems to automatically design production systems have been reported in literature. While the support tools described by Mellichamp et al. (1990); Borenstein (1998); Lee et al. (2006) and Khan et al. (2011) generate single system design solutions for a specific design problems, only one approach has been described that generates multiple systems for a given production problem and allows the users to compare the alternatives (Michalos et al., 2012), yet the comparison focuses on performance aspects of the systems. Hence, using the reported approach to explore a large variety of solutions that fulfill design and performance requirements simultaneously appears to be difficult. The many opportunities that exist for allocating FAGs and products to multiple production cells make 


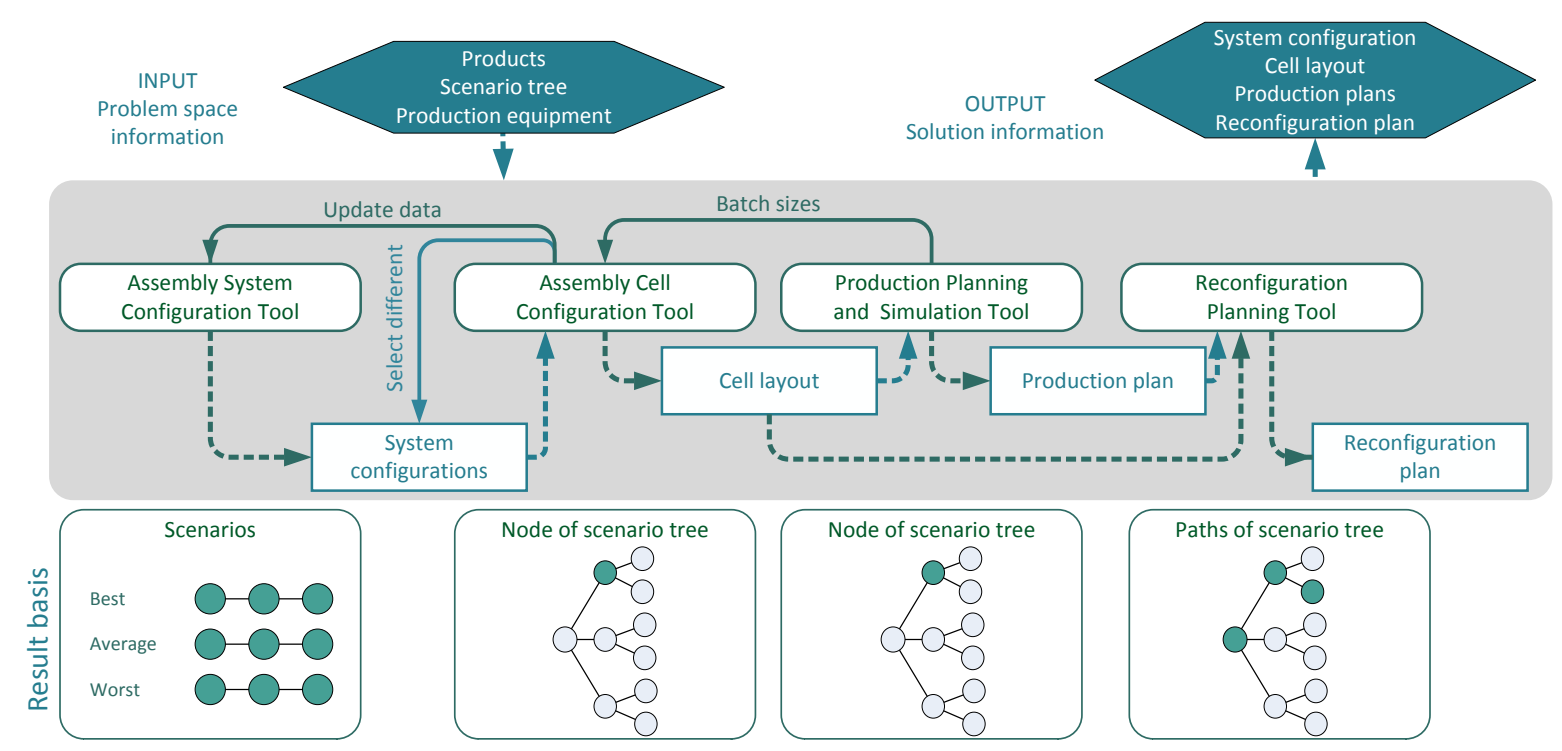

Figure 2: Design and management workflow for reconfigurable assembly cells.

possible a vast number of production system configurations. To exploit this freedom of system configuration, the tool aims at supporting decision-makers should allow to identify well-performing system configurations, respecting design and performance constraints at the same time.

Therefore, the main objective of the Assembly System Configuration tool is to automatically generate many configurations of the assembly system and to analyze their key performance indicators (KPIs) to enable the exploration of the design space, which is supported by visualizing all generated system configurations and their performances in versatile interfaces (Figure 3). To achieve this objective, multiple design and analysis steps are executed in an automated way for each candidate solution visualized. At first, the tool determines the number of assembly cells in the system, afterwards the production equipment is selected and assigned to the cells. In the last design step, the products are assigned to cells. Once the design is completely specified, the KPIs of the synthesized solution can be determined. All candidate solutions and their performances are visualized to the decision-maker. After exploring the various configurations and their KPIs, the decision-makers can exclude infeasible regions of the design space by imposing constraints and select the most suitable solutions based on their design and performance characteristics. By iteratively specifying constraints, generating matching solutions and assessing the resulting solutions, the knowledge-based tool enables concurrent assessment of various options to configure the production system, and facilitates developing feasible assembly system configurations.

As basis for the generation of system designs, the tool analyses the information about the expected product demand and technical information of each product. Therefore, the input data (see also Tables 6 and 5 in Section 10) contains the technical description of the production processes of the various products as well as demand situations that represent the uncertain evolution of the market in terms of production volumes. Furthermore, the data provide information about the production equipment (e.g. FAGs, 7-axis robots), in terms of investment cost, processing speed and shop floor requirement. Based on this information, the minimum capacity requirement for each multi-cellular configuration is calculated and subsequently multiplied by a scaling factor to estimate the respective upper bound of the required capacity. This scaling factor can be controlled by the decision-maker to specify the resulting sizes of systems and allowed maximum of capacity reserve.

Afterwards, the capacity bounds are converted into bounds for the system design parameters, resulting in discrete minimum and maximum values for the number of equipment components (e.g. for the number of FAGs for mechanical joining). In this manner, the ranges for the number of cells and equipment instances are determined. Once these boundaries are known, an algorithm incrementally instantiates random values in these intervals to complete the system description. After the sys- 
tem design is completely specified, a heuristic-based algorithm allocates the processes required to manufacture the product portfolio to the specific cells and resources.

Thereafter, the KPIs of the total system and its different sub-systems are calculated, such as the total investment, required floor space, expected utilization of productions cells, logistics cost, storage cost, estimated product-related cost and lead-time. In case the parameter values are outside of the feasible range, e.g. if the allocation requires more capacity or the system covers more area than specified by the user, the solution is discarded and a new one generated instead.

As output of the tool, the design and performance aspects of the various generated system configurations are visualized in interfaces that allow decision-makers to interactively assess the solutions. Due to the many opportunities for configuring the system with regard to production resources and product allocation, an enormous number of system designs can be generated by the tool. To generate preferably relevant solutions, various design strategies are implemented to result in three different system types: (i) system designs in which userdefined product families are produced in separate cells; (ii) system designs in which products are allocated to the cells without transfer between cells; (iii) system designs in which each product can be transferred between the production cells and following it's own route. Due to the random influences during system configuration, still a high number of designs can be generated, thus the tool provides decision-makers the opportunity to perform further assessments on the solution space. The visualization of the various design and performance aspects of system configurations can be adjusted to suit user preferences and encourages to compare the configurations, for instance by selecting the most relevant performance parameters to contrast the solutions on the Pareto-fronts for these parameters. Eventually, requirements can be formulated for all performance and design properties of solutions. By synthesizing new solutions that match those requirements and iteratively adding more requirements, the users can narrow down the number of solutions according to their constraints.

In this way the automated design procedure and setbased presentation of the solutions aims at creating an awareness of alternative concepts for organizing the production system, simultaneously reducing the time needed for conceptualizing and analyzing a large number of alternative multi-cell configurations.

\subsection{The Assembly Cell Configuration tool}

After the identification of a promising system configuration through the application of the Assembly Sys- tem Configuration tool, the Assembly Cell Configuration tool is used to increase the level of detail of the design in terms of the physical layout, the task sequencing and a dynamic performance evaluation using a fast analytical method, also considering failure and repair probabilities of each FAG. The Assembly Cell Configuration tool considers as inputs (i) the resources and products assigned to the cell, obtained from the Assembly System Configuration tool, and (ii) the production requirements coming from the scenario tree. With this information, the tool generates a set of detailed layout configurations and their task sequences, also considering the alternative execution modalities.

An execution modality is a possible technically feasible arrangement of the equipment and the associated sequence of tasks to execute a set of operations on a product. Together with the definition of the layout, also the execution modality for each $F A G$ is defined. The alternative execution modalities (illustrated in Table 2) are:

1. Part worked inside the module. In this case a FAG has its own working cube. The part is transported into the working cube from the input station (or from the previous machine) by a 7-axis robot with a proper handling tool. Once the part is inside the module, it is processed.

2. Part blocked in the fixture while FAG works it. In this case, the $F A G$ takes advantage of an external fixture to work on a part. The 7-axis robot is used to move the part to and from the fixture.

3. Part blocked in the fixture while the 7-axis robot works on it. In this case the 7-axis robot operates the process on the part while it is blocked in the fixture. The 7-axis has to load a specific tool taken form the $F A G$ (e.g. glue gun for an adhesive joining) in order to execute the operations.

4. Part handled by the 7-axis robot while the FAG works on it. In this case, the 7-axis robot handles the part while the equipment in the $F A G$ execute the process.

Hence, choosing an execution modality together with a FAG affects the layout of the cell as well as the task sequencing of the assembly operations and, consequently, also the performance associated to these choices.

In order to calculate the performance of an assembly line configuration, we define the state of the system through a vector $s=\left|c_{1}, c_{2}, \ldots, c_{N}, r\right|$ where: 


\begin{tabular}{|l|l|} 
Robot R1 loads the part from the turn table (1) \\
$\mathrm{R} 1$ moves to the module \\
$\mathrm{R} 1$ releases the part in the fixture (2) \\
$\mathrm{R} 2$ joins the sub-assemblies \\
$\mathrm{R} 1$ loads the part \\
$\mathrm{R} 1$ moves to the turn table (1) \\
$\mathrm{R}$ 1 releases the part in the mould \\
$\mathrm{R} 1$ loads the part from turn table (1) \\
$\mathrm{R} 1$ moves to the fixture (2) \\
$\mathrm{R} 1$ releases the part in the fixture \\
$\mathrm{R} 2$ joins the sub-assemblies \\
$\mathrm{R} 1$ loads the part \\
$\mathrm{R} 1$ moves to the turn table (1) \\
$\mathrm{R} 1$ releases the part in the mould \\
$\mathrm{R} 1$ loads sub-assemblies on the fixture (1) \\
$\mathrm{R} 1$ moves to the module (2) \\
$\mathrm{R} 1$ loads the needed tool \\
$\mathrm{R} 1$ moves to the fixture (1) \\
$\mathrm{R} 1$ joins the parts \\
$\mathrm{R} 1$ moves to the module (2) \\
$\mathrm{R} 1$ releases the tool and loads the clamp \\
\hline
\end{tabular}

Table 2: Execution modalities description: for each one an exemplar configuration and task sequencing is given.

- $c_{i}, 1 \leq i \leq N$, describes the state of the $i$ th station in the line, assuming the values: Operative $(O)$, Starved $(S)$ and Blocked $(B)$.

- $r$ describes the state of the 7-axis robot assuming values in $[0,1, \ldots, N, N+1]$ where: 0 is the idle state and the values $i \in[1, \ldots, N+1]$, are operative states in which the 7-axis robot is processing a part that will be transported to the station $i . N+1$ is a dummy station representing the completion of the processing.

In order to describe the system dynamics, the following considerations apply:

1. parts are moved only by the 7-axis robot;

2. components are always available;

3. no additional storage is possible in the stations, hence, they are blocked after the end of service until the 7-axis takes the processed part;

4. the 7-axis robot moves the parts only if the destination station is empty;

5. the 7-axis robot is always able to unload a part that has been processed inside the last station.

6. the load and unload times are negligible;

7. all the machines of the system work asynchronously in relation to the others.
The dynamics of the system are described by logical expressions modeling the sequence of events. We provide the description of an event in terms of its pre-conditions and post-conditions: i) $<$ pre - conditions $>$ is the logical expression describing under which conditions an event can occur; ii) $<$ post - conditions $>$ describes how the state of the system will change if such event occurs. We denote an event with $<$ pre - condtions $>\rightarrow<$ post - condtions $>$. In sake of brevity, each logical expression will indicate only those variables that are directly involved in the event. Given a generic state $s$, the events describing the system dynamics are the following:

$$
\begin{gathered}
c_{i}=O \wedge c_{i+1}=S \wedge r=I \\
\rightarrow c_{i}=S \wedge r=i+1,2 \leq i \leq N \\
c_{i}=O \wedge\left(c_{i+1} \neq S \vee r \neq I\right) \\
\rightarrow c_{i}=B, 2 \leq i \leq N \\
c_{1}=O \wedge c_{2}=S \wedge r=I \rightarrow c_{1}=O \wedge r=2 \\
c_{1}=O \wedge\left(c_{2} \neq S \vee r \neq I\right) \rightarrow c_{1}=B \\
r=k \wedge k>1 \wedge \exists i>1:\left(c_{i}=B \wedge c_{i+1}=S\right) \\
\rightarrow c_{k}=O \wedge c_{i}=S \wedge r=i \\
r=k \wedge k>1 \wedge c_{1}=B \wedge c_{2}=S \\
\rightarrow c_{k}=O \wedge c_{i}=O \wedge r=2 \\
r=k \wedge k>1 \wedge \nexists i:\left(c_{i}=B \wedge c_{i+1}=S\right) \\
\rightarrow c_{k}=O \wedge r=I
\end{gathered}
$$

Events (1) and (2) model the end of a service at the $i$ th station. In particular, (1) corresponds to the case in which the 7-axis robot is idle and can remove the part from station $i$ immediately while in (2) the 7-axis robot is already processing a part. In the first case $c_{i}$ will be blocked whereas in the second it will be starved. Events (3) and (4) refer to the first station returning operative after working due to the continuous availability of raw parts. Events (5) and (6) describe the case in which the 7-axis finishes to move a part and takes another part from another station $i$. The difference between these two events is that station $i$ always returns operative when the part is removed whereas every other working cubes get starved because it must wait for a new part. Event (7) 
describes the 7-axis robot becoming idle when the system does not contain any other part ready to be transported. As further constraint, we assume that the the 7-axis serves the station closest to the end of the line amongst those that are blocked. We assume that every change of state occurs according to Markovian distributions and the underlying stochastic process is a Continuous Time Markov chain (CTMC). Therefore, in the most simple scenario, all the service times are exponential distributions.

Unfortunately, the exponential distribution is frequently a bad candidate for representing actual distributions of real systems. To manage this problem, we consider phase-type distributions $(P H)$ to model the processing times. A random variable $T$ is $P H$ distributed if its cumulative distribution function $(c d f)$ corresponds to the time till absorption of a CTMC given a pre-fixed initial distribution. The more detailed structure of $P H$ distributions allows the fitting of general distributions by matching their higher moments (Horvath and Telek, 2007). Due to the introduction of $\mathrm{PH}$ distributions the structure of the underlying CTMC gets slightly more complicated because every state of the system is expanded in order to consider also the detailed information about the aging of the distributions. This lead to an infinitesimal generator, denoted by $Q$, that is composed of blocks, referred as $Q_{s, s^{\prime}}$, that describe the motion of the process between two states of the system, that can be used to calculate the time to absorption of the described Continuous Time Markov Chain and, hence, the lot completion time.

\subsection{The Production Planning and Simulation tool}

In general, production planning is responsible for matching the supply with demand, by balancing the internal capacities with the order stream and transforming the customer needs into production orders (Meyr et al., 2015). Medium-term planning and scheduling problems - considering reconfigurable resources - are solved by Li et al. (2014) and by Safaei and TavakkoliMoghaddam (2009), however, these solutions cannot be applied in the proposed workflow, due to the different system architecture (constraints) and/or objectives. The execution of plans directly incurs operative costs that need to be respected when seeking for the costoptimal reconfiguration strategy. Therefore, the production planning tool of the workflow is aimed at predicting the future-expected operation related costs, characterizing a given cell configuration besides the forecast order stream. The proposed production planning method is able to handle the reconfigurable cells by modulespecific constraints that prevent to hurt capacity limita- tions, thus resulting in feasible plans. Besides the planning, the second major part of the Production Planning and Simulation tool is a novel discrete-event simulation model, implemented to execute the calculated plans by adding realistic random events (e.g. machine breakdowns) and representing the possible random-nature of the production parameters. As the cells have fix parts and also some changeable modules, a novel simulation modeling technique was applied, reflecting the real physical architecture and operation of the cells by having static model elements, as well as dynamicallycreated blocks.

The production planning module calculates the production lot sizes, based on the contractual delivery volumes and the given system configuration with the specified number of reconfigurable cells $|C|$, and exchangeable modules $j \in J$. According to the scheme of Pochet and Wolsey (2006), the formulated model can be classified as a small bucket lot-sizing model with backlogging ( $L S-C-B / M 1)$, including additional system-specific constraints. The $F A G$ s have a common resource pool with a specified amount $n_{j}$ of resources from each type. In the planning model, a discrete time horizon is considered, consisting of equal length $t^{p}$ periods. In the overall system with multiple cells, different products $p$ are produced, each having a specific total machine cycle time $t_{p}^{m}$, and total manual cycle time $t_{p}^{h}$, besides, product-independent changeover time $t^{s}$ is considered. The technological requirements of the assembly tasks are represented by the amount of modules from type $j$ that need to be installed at the cell $r_{j p}$, and the technological constraints are summarized in a compatibility matrix $a_{p c}$, whose element equals to 1 if product $p$ can be assembled in cell $c$, and 0 otherwise. In the specified planning model, contractual delivery volumes are calculated, specifying the amount $d_{p t}$ from product $p$ should be delivered in time $t$. The decision variables determine the production lots $x_{p t c}$, specifying the volume of product $p$ assembled in cell $c$ in period $t$. Assembled products can be either delivered to the customer $\left(s_{p t}\right)$ or kept in the inventory $\left(i_{p t}\right)$, however, the latter is associated with certain costs. Besides the assignment of production lots and machine capacities, an important decision is to determine the headcount of operators $h_{c t}$ working at cell $c$ in period $t$. The production planning problem is formulated by a mixed integer linear programming model as it follows.

$$
\operatorname{minimize} \sum_{p \in P} \sum_{t \in T}\left(c^{b} b_{p t}+c^{s} i_{p t}\right)+\sum_{c \in C} \sum_{t \in T} c^{h} h_{c t}
$$




$$
\begin{gathered}
\sum_{c \in C} \sum_{p \in T} r_{j p} y_{p t c} \leq n_{j} \quad \forall t, j \\
\sum_{p \in P}\left(t_{p}^{h} x_{p t c}+t^{s} r_{p t c}\right) \leq t^{p} h_{c t} \quad \forall c, t \\
\sum_{p \in P}\left(t_{p}^{m} x_{p t c}+t^{s} r_{p t c}\right) \leq t^{p} \quad \forall c, t \\
s_{p t} \geq d_{p t} \quad \forall p, t \\
\sum_{p \in P} y_{p t c} \leq 1 \quad \forall c, t \\
\forall c, t, p \quad \forall>t^{p} /\left(\max _{p \in P} t_{p}^{m}\right) \\
x_{p t c} \leq \Lambda y_{p t c} \quad \forall c, t, p \\
x_{p t c} \geq y_{p t c} \quad \forall c, t, p \\
y_{p t c} \leq a_{p c} \quad \forall c, t, p \\
r_{p t c} \leq y_{p t c} \quad \forall c, t, p \\
r_{p t c} \geq y_{p t c}-y_{p, t-1, c} \quad \forall \quad \forall, t, p \\
r_{p t c}+\sum_{q \in P}\left(y_{q t c}-r_{q t c}\right) \leq 1-y_{p, t-1, c} \quad \forall p, t \\
i_{p t}-b_{p t}=i_{p, t-1, c}-b_{p, t-1, c}-s_{p t}+\sum_{c \in C} x_{p t c} \\
r_{p t c}, y_{p t c} \in\{0,1\} \quad x_{p t c}, s_{p t}, i_{p t}, b_{p t} \in \mathbb{Z}^{+}
\end{gathered}
$$

The objective of production planning is to minimize the operative costs, consisting of the sum of backlog, inventory holding and operator costs (8). The constraints express the module (FAG) requirements (9), human (10) and machine (11) capacity requirements. The contractual volumes need to be delivered on time (12), capacity and inventory shortage occur backlogs. Constraints (1318) represent the changeover requirements when a new product is to be produced in a given cell. The balance equation (20) is responsible for linking the subsequent time periods with each other through the delivery, inventory and production volumes.

\subsection{The Reconfiguration Planning tool}

The Reconfiguration Planning tool addresses the layout decision process of a single cell in a multi-period time horizon. As described in Section 3, we assume that the market evolution can be modeled through a scenario tree in which each node represents a set of requirements related to product mix and volumes. To match the evolution of the requirements over time, an assembly cell needs to be suitably reconfigured. Reconfiguration refers to the change, insert or move one or more pieces of equipment in the assembly cell. In the Reconfiguration Planning tool, all possible evolutions of the market requirements (i.e., a specific path from the root of the scenario tree to a leaf) are taken into account in the formulation of an optimization problem, to find the best configuration and reconfiguration plan for all the different paths. The aim is achieving robustness over the whole scenario tree, e.g., acquiring resources and equipment in advance (proactive approach) or waiting for the occurrence of a specific event to proceed with a proper reconfiguration (reactive approach). The optimization problem is :

$$
\begin{aligned}
& \text { minimize }\left(I C\left(z_{c 0}\right)+O C\left(z_{c 0}\right)\right. \\
& \left.+\sum_{\omega \in \Omega_{s}} \pi(\omega) \frac{I C\left(z_{c \omega} \mid z_{c 0}\right)+O C\left(z_{c \omega} \mid z_{c 0}\right)}{(1+q)^{\text {stage }_{\omega}}}\right)
\end{aligned}
$$

subject to

$$
\begin{aligned}
& I C\left(z_{c t}\right)=\sum_{e}^{E} I C\left(z_{c t}\right)_{e}+\sum_{f}^{F} I C\left(z_{c t}\right)_{f} \\
& I C\left(z_{c t}\right)_{e}= \begin{cases}\operatorname{cost}_{i n v}(j) & \text { if } e=j \\
0 & \text { otherwise }\end{cases} \\
& I C\left(z_{c t}\right)_{f}=T C(f) \\
& O C_{z_{c t}}=T_{\text {total }}\left(z_{c t}\right) \cdot \cos t_{o p} \\
& T_{\text {total }}\left(z_{c t}\right)=\operatorname{PerfEvo}\left(z_{c t}, d_{p}(\omega), l_{p}(\omega), V\right) \\
& z_{c t}=\operatorname{ConfGen}\left(S_{p}(\omega), J, V\right) \\
& \omega \in \Omega_{s} \quad z_{c t} \in Z \quad e \in E \quad f \in F \quad v \in V \\
& v \in K \quad z_{c t}=(E, F, V)
\end{aligned}
$$

The configuration strategy depicted aims at minimizing the objective function in Equation (22) representing the expected value of the overall cost over all the scenarios. In particular, $I C$ and $O C$ are investment and operational cost respectively, calculated by using a given layout $z_{c t}$ in scenario node $\omega$ considering $\Omega_{s}$ as the set of scenario nodes under study. Equation (22) is divided in two sub-functions, the first takes into account the initial configuration decisions $z_{c 0}$ while the second one considers future decisions $z_{c \omega}$, computing the expected values of future costs. A discount rate $q$ is applied being stage $e_{\omega}$ the time stage of the considered scenario node.

In both cases, investment costs are calculated according to Equation (23) taking into account investment cost for each module $j \in J$ included in the layout (Equations (24)) and the tools (Equations (25)). In particular, 
Equation (24) assigns the investment cost to each module type $j$ chosen and indicated by the set $e \in E$; in the same way, the purchasing cost for tools $f \in F$ is considered in Equation (25). In Equation (26), the operational cost function is described as the product of the total time $T_{\text {total }}\left(z_{c t}\right)$, calculated exploiting performance evaluation results, and the hourly operational cost $\operatorname{cost}_{o p}$. The total time is the time to produce all the parts required in a given scenario $\omega$. Its formalization is included in Equation (27), in terms of the quantity to be produced $d_{p}(\omega)$, the batch size $l_{p}(\omega)$ and the execution modality selected $V$. Only feasible layout configurations are considered for the optimization.

\subsection{Interoperability and integration of the platform}

To achieve an integration of the individual tools, all of them operate on the same database, enabling to use the tools sequentially. The central database ensures the interoperability of the tools by means of the Core Manufacturing Simulation Data (CMSD) standard model (Lee et al., 2011). Moreover, workflow-specific interfaces make possible the transfer of data between the tools.

The tools are typically executed in the sequence presented in the order of the workflow in Figure 2. Nevertheless, the coupling between the tools makes possible to exploit the information feedback between them. The intention behind this is, that in case a solution turns out to be infeasible at a certain stage in the workflow, the root solution can be refined by the tool working upstream in the workflow. In the proposed methodology, three main feedback loops are defined to exchange information among the modules.

After identifying a favorable multi-cell system configuration with the Assembly System Configuration tool, an individual cell is considered in detail using the $A s-$ sembly Cell Configuration tool. In this step, it is important to evaluate whether the selected FAGs can be arranged into a layout that is still compliant with the assumptions used in the Assembly System Configuration tool with regards to cycle times and available capacity considering the associated performance evaluated. In case the production rate does not reach the target value, the bottleneck operations and the corresponding modules are identified. Based on this information another solution from the Assembly System Configuration tool is used as input for the Assembly Cell Configuration tool; or the input data for the Assembly System Configuration tool is redefined to synthesize and evaluate new system configurations (Figure 2).

The second main feedback loop is implemented to backlink the results of the Production Planning and
Simulation tool to the Assembly Cell Configuration tool. In this case, the information added on the lower level primarily refers to the batch sizes, coming from the production planning tool. Since fixed batch sizes are assumed when calculating the layout configuration and the corresponding process sequence, the planning tool could operate variable batch sizes in order to match the requirements of the customers and, thus, the average batch sizes could be different from what initially defined. In this case, the evaluation of the performance is operated again considering the new average batch sizes.

A third feedback refers to operational costs calculated by the Production Planning and Simulation tool. Grounding on a simulation approach, operational costs can be calculated precisely considering the detailed logistics constraints, providing feedbacks to the Reconfiguration Planning tool that might change the reconfiguration sequence along the horizon. Hence, the optimal solution could change and a new optimal sequence of reconfiguration steps must be identified.

\section{Industrial application case}

\subsection{Presentation}

In the following sections, application of the proposed approach to an automotive spare part assembly case is presented. As described in Section 1, the application environment is characterized by a high-mix low-volume demand, considering four different products in a 3 time periods horizon lasting three months (480 hours each). In every time period, the product mix and volumes could change accordingly to market request.

In addition, due to market uncertainty a scenario tree is used: each scenario represents a possible market situation to be faced and the tree structure gives the precedence constraints between different scenario nodes. The complete description of scenario nodes in terms of demand requested and precedence relations is given in Table 6 (Appendix). Each part taken into account has its own assembly process described through the sequence of assembly operations, the specific tools (or equipment) used and the duration of operations (included in Table 6, Appendix). The joining technologies taken into account are typical for the assembly of car bodies, such as different types of mechanical joining (nut pressing, riveting) the resistance and the adhesive joining. Each of these technologies is embodied by fixed equipment (the $F A G$ ) and exchangeable tools installed on modular devices, as described in Section 5.2. For this reason, the process requirements described in Table 6 (Appendix) include both the tool type represented with $\mathrm{T \#}$, and the processing time in seconds. 
For each $F A G$ and the modular production equipment components the specific $2 D$ dimensions are known, which are used during analysis and layout generation, as well as technological indication regarding failure and repair rate. In the evaluation, we will take into account also information such as the purchasing price for specific equipment (from the minimum one of 10,000 $€$ of the modular device, to the maximum one of $120,000 €$ of the control unit), operative hourly cost $(50 € / h)$ or the time and cost for reconfiguration(2 working weeks, $20,000 €$ respectively). All these data are included in Table 5 (Appendix).

Based on this information, the integrated approach is applied to the presented problem. In the following Sections, the application of each tool is described and the results for a single scenario are presented.

\subsection{Assembly System Configuration tool application}

Firstly, the Assembly System Configuration tool uses available information about expected situations of future product demand (cf. best-, average- and worst-case in Table 6, Appendix) to generate design candidates that can be used to face these scenarios. To this aim, instances of the equipment components from the database (cf. Table 5, Appendix) are clustered into multiple assembly cells and products are allocated afterwards. Due to the random factors that vary specific system design parameters, various production systems are generated for the presented problem. The resulting system configurations embody different production strategies (cf. column Alias, Table 3) which are analyzed with regard to their performance.

Afterwards, the design synthesis tool visualizes the various generated designs and related performance parameters to the decision-maker: Using the adjustable GUI of the tool (cf. Figure 3) for exploring and comparing solutions, decision-makers can exclude solutions by specifying design and performance constraints for the design candidates to eventually obtain various, feasible solutions, such as the ones shown in Table 3.

Decision-makers can assess the configurations with regard to their varying cost profiles that are caused by differing degrees of resource clustering and matching product allocation. The distinct performance of the presented configurations stems from the allocation of bottlenecks and amount of required changeovers in the system (both affecting direct production cost), but also from the higher number of transports and higher stock levels in the multi-cell solutions. Additionally to these operational KPIs, decision makers can take into account required investment and space, as well as the degree of

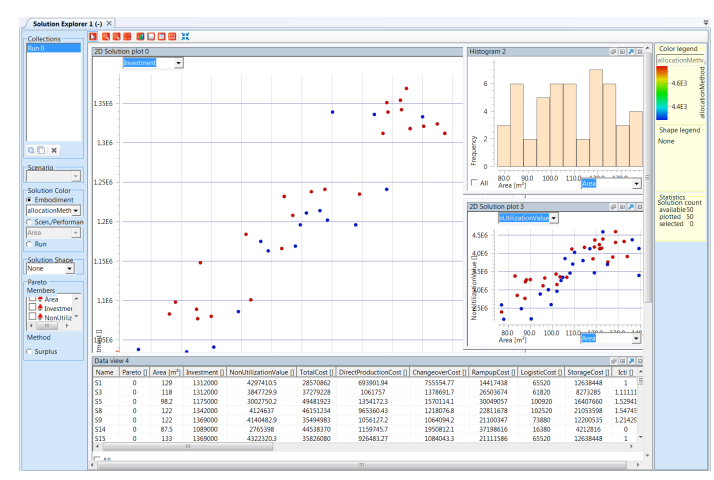

Figure 3: GUI of the Assembly System Configuration tool.

utilization (cf. Table 3). In the presented case, the single cell configuration may be the most suitable solution, if decision-makers seek for a solution that strikes a balance of investment and total cost.

\subsection{Assembly Cell Configuration tool application}

The Assembly Cell Configuration tool considers the pieces of equipment identified in the previous step and arrange them in alternative layouts. The different ехесиtion modalities described in Section 5.2 are considered in order define the task sequencing and set up the performance evaluation model.

To illustrate the tool, we consider two different layouts $(A$ and $B)$ generated in relation to two different execution modalities for all the assembly operation, namely number 1 and 4. The two layouts pursue the Single cell architecture coming from the Assembly System Configuration tool where all the products are processed in the same cell. According to the scenario tree, we consider the first time period only, in scenario $\omega_{0}$, and test the two layouts producing part types 1 and 3 . The two layouts are represented in Figure 5, Appendix.

The different execution modalities considered, entails a different task sequence for the assembling operations and, consequently, their performances are different. Table 7 reports the throughput for the two solutions showing that layout $A$ performs significantly better compared to layout $B$. The reason is that the for the latter, the 7axes robot is used to move parts but also to hold them while the FAGs work. Hence, the 7-axes is loaded more, compared to layout $A$, causing the assembly process to take more time. In addition to the performance evaluation, also the different costs associated to the two solutions must be taken into consideration, as reported in Table 7 (Appendix), to support the selection of the best alternative. 


\begin{tabular}{|c|c|c|c|c|c|c|c|}
\hline $\begin{array}{l}\text { Solution } \\
\text { lias }\end{array}$ & $\begin{array}{c}\text { System } \\
\text { configuration }\end{array}$ & $\begin{array}{r}\text { Area } \\
\text { occupied }\left[\mathrm{m}^{2}\right]\end{array}$ & $\begin{array}{r}\text { Initial } \\
\text { investment }[€]\end{array}$ & $\begin{array}{r}\text { Direct prod. } \\
\text { cost }[€]\end{array}$ & $\begin{array}{r}\text { Logistics and } \\
\text { storage cost }[€]\end{array}$ & $\begin{array}{r}\text { Total } \\
\operatorname{cost}[€]\end{array}$ & $\begin{array}{r}\text { Non-utilized } \\
\text { capacity value }[€]\end{array}$ \\
\hline Single cell & $\begin{array}{l}\text { Products }\{1-4\}->\text { Cell1: [Operation1, Op2, } \\
\text { Op3, Op4]; }\end{array}$ & 51 & 515,000 & 12,570 & 13,135 & 25,705 & 116,181 \\
\hline Dedicated cells & $\begin{array}{l}\mathrm{P}\{1\}->\mathrm{C} 1:[\mathrm{Op} 1, \mathrm{Op} 2, \mathrm{Op} 3, \mathrm{Op} 4] \\
\mathrm{P}\{2\}->\mathrm{C} 2:[\mathrm{Op} 2, \mathrm{Op} 3, \mathrm{Op} 4] \\
\mathrm{P}\{3\}->\mathrm{C} 3:[\mathrm{Op} 1, \mathrm{Op} 2] \\
\mathrm{P}\{4\}->\mathrm{C} 4:[\mathrm{Op} 1, \mathrm{Op} 2]\end{array}$ & 142 & $1,650,000$ & 8,758 & 13,135 & 21,893 & 403,599 \\
\hline Split processes 1 & $\begin{array}{l}\mathrm{P}\{1-4\}->\mathrm{C} 1:[\mathrm{Op} 1, \mathrm{Op} 2] \\
\mathrm{P}\{1-2\}->\mathrm{C} 2:[\mathrm{Op} 3, \mathrm{Op} 4]\end{array}$ & 67 & 749,000 & 9,856 & 19,535 & 29,391 & 177,394 \\
\hline Split processes 2 & $\begin{array}{l}\mathrm{P}\{1 ; 3 ; 4\}->\mathrm{C} 1:[\mathrm{Op} 1] \\
\mathrm{P}\{1-4\}->\mathrm{C} 2:[\mathrm{Op} 2, \mathrm{Op} 3, \mathrm{Op} 4] ; \\
\quad \mathrm{P}\{1 ; 3 ; 4\}->\mathrm{C} 1:[\mathrm{Op} 1] ;\end{array}$ & 70 & 764,000 & 13,777 & 24,870 & 38,647 & 177,223 \\
\hline Split processes 3 & $\begin{array}{l}\mathrm{P}\{1-4\}->\mathrm{C} 2:[\mathrm{Op} 2] \\
\mathrm{P}\{1 ; 2\}->\mathrm{C} 3:[\mathrm{Op} 3] \\
\mathrm{P}\{1 ; 2\}->\mathrm{C} 4:[\mathrm{Op} 4]\end{array}$ & 104 & $1,247,000$ & 11,265 & 33,470 & 44,735 & 300,485 \\
\hline
\end{tabular}

Table 3: Generated system configurations of the Design Synthesis Tool.

\subsection{Production Planning and Simulation tool applica- tion}

Applying the Production Planning and Simulation tool, one can analyze the future-expected operative costs and production batch sizes, based on the contractual delivery volumes known already in the early design stage. Relying on the defined application case, the inputs of the tool are the system configurations in the subsequent time periods, as well as the delivery volumes agreed with the customers. The main purpose of the tool is to refine the estimation on the batch sizes: in case of the previous tool of the workflow, average batch sizes and frequency of the deliveries are considered, while in this case they are calculated by matching the order stream with the detailed system structure. Executing these plans in the discrete-event simulation model of the system, realistic operative costs can be calculated that consider additional information compared to the previous module, as inventory, personnel and also backlog costs can be determined. The refined operative costs are meaningful feedback information that can be applied by the Reconfiguration Planning tool to select the cost-optimal reconfiguration strategy. Besides, the batch sizes can be utilized by the Assembly Cell Configuration tool to evaluate and/or refine the cell configuration.

In the experiments, four different scenarios are analyzed by the planning and simulation models. In the first scenario (contractual), the contractual delivery volumes and frequency were applied (represented by variables $d_{p t}$ ), evaluating the solutions calculated by the $A s$ sembly Cell Configuration tool considering ideal order stream. In the other three scenarios (Sc 1-3), delivery frequencies are increased by splitting the total volumes in smaller parts. In these scenarios, the total volumes are the same, while the delivery frequency is in- creased by $10-20-30 \%$ subsequently. This results in smaller production batch sizes, more changeovers and thus higher operative costs, which often occur in the real life. All the experiment results are reported in Table 8, Appendix.

The results show that even in the contractual case, the operative costs are higher than the ones considered by the previous modules. This refined information can be applied by the Reconfiguration Planning tool, if one assumes that contractual volumes will not change in the future. A more conservative solution is applying the operational costs resulted by on of Sc 1-3 scenarios, where smaller batch sizes and higher costs are resulted.

\subsection{Reconfiguration Planning tool application}

The Reconfiguration Planning tool exploits the results of the previous tools to select a robust robust solution with minimum cost, i.e., a configuration able to face the considered market evolutions together with a proper reconfiguration plan. The solution selected for the case study is the one in Figure 4 for the three time periods. All the FAGs and modular equipment needed for the whole time horizon are installed in the initial configuration. In order to cope with the production of different part types, a setup is needed to switch tools and molds. The modular solution adopted provides fast and swift setup capability, whose impact on the production performance is low. We estimate only 30 minutes to switch from the production of one part type to another. The solution provided adopts execution modality number 1 among the alternative ones available, as described in Section 5.2.

Table 4 reports the overall costs for the scenario $\omega_{0} \rightarrow \omega_{1 B} \rightarrow \omega_{2 C}$, associated with the solution proposed by the robust approach. This one is compared with two alternative solutions, i.e., the single path optimum approach and the initial node optimum approach. 


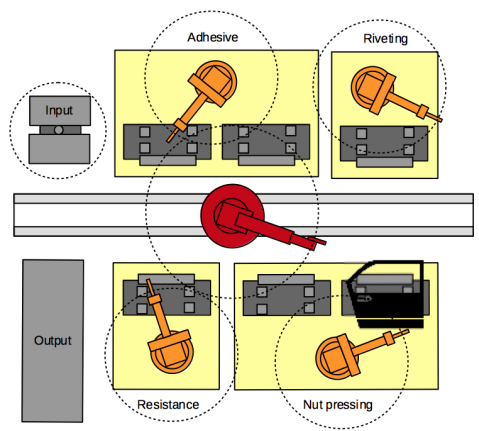

Figure 4: Robust cellular layout able to be easily reshaped by changing the modules in the FAGs. This solution can face the production requirements for all the scenarios.

The first one takes into account a single scenario $\left(\omega_{0} \rightarrow\right.$ $\left.\omega_{1 B} \rightarrow \omega_{2 C}\right)$ and looks for the best configuration in each time period; the second one considers the best solution for the first time period only. The comparison considers investment, reconfiguration and operational costs showing that the robust solution is the minimal-discountedcost configuration, able to avoid the need of reconfiguration actions (as needed in the single path optimum approach). The robust approach suggests the installation of pieces of equipment in advance respect to the real need; pursuing this strategy no reconfiguration costs are incurred, being their impact relevant $(20,000 €)$ in relation to the initial configuration. The robust approach solution also give up in pursuing the local optimality in the second time period (compared with the second strategy solution) addressing global optimality on all the time periods. Notice that, the myopic approach pursuing the initial optimum (the third strategy considered) provides a solution not feasible in the last time-period.

\begin{tabular}{|c|c|c|c|c|c|}
\hline & Cost Type & $t_{0}$ & $t_{1}$ & $t_{2}$ & Total \\
\hline \multirow{4}{*}{$\begin{array}{l}\overrightarrow{\underline{n}} \\
\overline{0} \\
\stackrel{0}{0}\end{array}$} & Investment & 557,640 & - & 18,000 & 575,640 \\
\hline & Operational & 9,955 & 10,323 & 13,399 & 33,678 \\
\hline & Reconfiguration & - & - & - & - \\
\hline & Total (discounted) & $\mathbf{5 6 7 , 5 9 5}$ & 9,647 & 27,426 & 604,668 \\
\hline \multirow{4}{*}{ 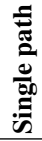 } & Investment & 547,640 & - & 28,000 & 575,640 \\
\hline & Operational & 9,955 & 10,380 & 13,399 & 33,735 \\
\hline & Reconfiguration & - & 20,000 & 20,000 & 40,000 \\
\hline & Total (discounted) & $\mathbf{5 5 7 , 5 9 5}$ & 28,393 & 53,629 & 639,617 \\
\hline \multirow{4}{*}{ 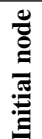 } & Investment & 547,640 & - & & 547,640 \\
\hline & Operational & 9,955 & 9,428 & & 19,384 \\
\hline & Reconfiguration & - & - & & \\
\hline & Total (discounted) & $\mathbf{5 5 7 , 5 9 5}$ & 8,812 & & $\mathbf{5 6 6 , 4 0 7}$ \\
\hline
\end{tabular}

Table 4: Comparison in terms of costs (all expressed in $€$ ) between the solution obtained with the presented robust approach and two alternative approaches, the single path optimum and the initial node optimum.
In order to demonstrate the robustness of the approach, we tested the selected solution in the most extreme scenarios in the tree, those with the minimum demand stream $\left(\omega_{0} \rightarrow \omega_{1 C} \rightarrow \omega_{2 F}\right)$ and the maximum one $\left(\omega_{0} \rightarrow \omega_{1 A} \rightarrow \omega_{2 A}\right)$. Since the behavior of the robust solution in the first time period of both scenarios $\left(\omega_{0}\right)$ has been already addressed (Table 4$)$, we focus the analysis on the other scenario nodes, considering the production volumes to be addressed and an availability time of $(480 \mathrm{~h})$. It is possible to calculate the time needed to satisfy the requirements in different scenarios exploiting the results of the performance evaluation. Specifically, 64h are needed in scenario node $\omega_{1 C}, 209 h$ in scenario node $\omega_{2 F}, 427 h$ in scenario node $\omega_{1 A}$ and $411 h$ in scenario node $\omega_{2 A}$. Hence, the robust solution is capable to satisfy the market requests in all the scenarios, including the extreme ones with the lowest occurrence probability.

\subsection{Evaluation of solutions applying feedback loops}

In the proposed approach we considered two feedback loops in the utilization of the tools. The first one is operated to feedback the layout configuration obtained from the Assembly Cell Configuration tool, based on the design selected by the Assembly System Configuration tool. In the proposed approach the feedback is embodied by the feasible layout that could be generate. Hence, based on this confirmation of the previous decision, it is not necessary to choose or generate alternative designs with the Assembly System Configuration tool.

An additional feedback loop, as presented in Section 5.3, it used to take advantage of the results of the Production Planning and Simulation tool in terms of actual lot sizes. As reported in Table 8, the need to consider all the details and constraints at the planning level, could entail different feasible lot sizes compared to the ones used in the Reconfiguration Planning tool (in Table 6, Appendix). This could affect operational cost, but also the performance, if the actual lot sizes are smaller. This information can be exploited in the overall approach in two ways:

- using the new estimated operational costs to identify a possible new optimal solution through the Reconfiguration Planning tool;

- using the new estimated batch sizes to search for alternative configurations using Reconfiguration Planning tool.

The first option can be implemented by simply substituting the new operational cost for each period (Table 
4, Appendix), 13, $714 €, 15,456 €$ and $17,779 €$ respectively, obtaining a refined discounted total cost of $617,050 €$, which is still the optimal solution. On the contrary, by using the new batch sizes in the Reconfiguration Planning tool, we obtain the same optimal configuration evolution (Figure 4) but with different operational costs, namely $10,932 €, 10,482 €$ and 13,665 $€$ for each period, with an overall discounted cost of $606,026 €$. Notice that the impact of the updated batch sizes accounted to more than $10,000 €$, thus providing a more accurate estimation of the cost for the considered solution, compared to what traditional configuration approaches do.

\section{Conclusions and outlook}

This paper proposes an integrated approach to support the design and management of reconfigurable assembly systems, which is designed around four decision-support tools that are connected through the presented workflow and ground on the same data structure. The approach enables decision-makers to derive use from different decision-support techniques for multiple decision stages by enabling design space exploration, layout optimization, production planning and simulation, as well as development of optimized reconfiguration strategies. Each module provides capabilities to speed up and support design and planning decisions, thus enabling to improve planning efficiency. The presented approach suggests to consider the design decisions at different levels of detail - system and cells and in the short-, medium- and long-term. Nevertheless, the main focus of the approach is to enable iterative loops and feedback that provide insight into alternative actions, which is made possible by integration of the modules in the workflow. This way, the tools can help to develop a suitable strategy to choose part and machine grouping, as well as help optimize performance and manage the long-term evolution of the cells. Moreover, we give an example how the applicability of individual decision-support approaches can be possibly increased by supporting decision-makers in considering the dependencies between the various decision steps. It is our ambition to stimulate other researchers to develop similarly modular concepts, which consider each module in the context of the related design and decision processes. A case study on an industrial example is presented to demonstrate the practical applicability and potential benefits of the approach.

The focus of future work will be on harmonizing the capabilities of the individual modules to obtain a workflow providing a balanced level of detail. In this context, the implications of reconfiguring multiple cells will be integrated into the Assembly System Configuration tool. Furthermore, consideration of multiple cells will be integrated into the Assembly Cell Configuration tool, and stochastic optimization approaches - regarding the production planning problem- will be applied in the Production Planning and Simulation tool to cope with the possible uncertainty of the parameters. According to the Reconfiguration Planning tool, further development will address the possibility of considering risk-based objective function, to address robustness in a more effective way.

\section{Acknowledgments}

This research has been partially supported by the EU FP7 Project No: NMP 2013-609087, RobustPlaNet Shock-robust Design of Plants and their Supply Chain Networks.

\section{Bibliography}

Battini, D., Faccio, M., Persona, A., Sgarbossa, F., 2011. New methodological framework to improve productivity and ergonomics in assembly system design. International Journal of industrial ergonomics 41 (1), 30-42.

Borenstein, D., 1998. Intelligent decision support system for flexible manufacturing system design. Annals of Operations Research 77, $129-156$.

Boysen, N., Fliedner, M., Scholl, A., 2007. A classification of assembly line balancing problems. European journal of operational research $183(2), 674-693$.

Ceglarek, D., Colledani, M., Váncza, J., Kim, D. Y., Marine, C., Kogel-Hollacher, M. Mistry, A., Bolognese, L., 2015. Rapid deployment of remote laser welding processes in automotive assembly systems. CIRP Annals - Manufacturing Technology 64, 389394.

ElMaraghy, H., Schuh, G., ElMaraghy, W., Piller, F., Schönsleben, P., Tseng, M., Bernard, A., 2013. Product variety management. CIRP Annals-Manufacturing Technology 62 (2), 629-652.

ElMaraghy, H. A., 2005. Flexible and reconfigurable manufacturing systems paradigms. International journal of flexible manufacturing systems 17 (4), 261-276.

Goldengorin, B., Krushinsky, D., Panos, P., 2010. Cell formation in industrial engineering: Theory, algorithms and experiments, 173179.

Guschinskaya, O., Dolgui, A., Guschinsky, N., Levin, G., 2008. A heuristic multi-start decomposition approach for optimal design of serial machining lines. European Journal of Operational Research 189, 902-913.

Guschinskaya, O., Gurevsky, E., Dolgui, A., Eremeev, A., 2011. Metaheuristic approaches for the design of machining lines. International Journal of Advanced Manufacturing Technology 55, 1122

Heilala, J., Helin, K., Montonen, J., 2006. Total cost of ownership analysis for modular final assembly systems. International Journal of Production Research 44, 3967-3988.

Horvath, A., Telek, M., 2007. Matching more than three moments with acyclic phase type distributions. Stoch. Models 23, 167-194. 
Hu, S. J., Ko, J., Weyand, L., ElMaraghy, H., Lien, T., Koren, Y., Bley, H., Chryssolouris, G., Nasr, N., Shpitalni, M., 2011a. Assembly system design and operations for product variety. CIRP AnnalsManufacturing Technology 60 (2), 715-733.

Hu, S. J., Ko, J., Weyand, L., ElMaraghy, H. A., Lien, T. K., Koren, Y., Bley, H., Chryssolouris, G., Nasr, N., Shpitalni, M., 2011b. Assembly system design and operations for product variety. CIRP Annals - Manufacturing Technology 60, 715-733.

Khan, M., Hussain, I., Noor, S., 2011. A knowledge based methodology for planning and designing of a flexible manufacturing system (fms). International Journal of Advanced Manufacturing Systems 13 (1), 95-109.

Koren, Y., Heisel, U., Jovane, F., Moriwaki, T., Pritschow, G., Ulsoy, G., Van Brussel, H., 1999. Reconfigurable manufacturing systems. CIRP Annals-Manufacturing Technology 48 (2), 527-540.

Koren, Y., Shpitalni, M., 2010. Design of reconfigurable manufacturing systems. Journal of manufacturing systems 29 (4), 130-141.

Lee, H., Srinivasan, M., Yano, C., 2006. A framework for capacity planning and machine configuration in flexible assembly systems. International Journal of Flexible Manufacturing Systems 18, 239268.

Lee, Y.-T. T., Riddick, F. H., Johansson, B. J. I., 2011. Core manufacturing simulation data-a manufacturing simulation integration standard: overview and case studies. International Journal of Computer Integrated Manufacturing 24 (8), 689-709.

Li, J., Wang, A., Tang, C., 2014. Production planning in virtual cell of reconfiguration manufacturing system using genetic algorithm. The International Journal of Advanced Manufacturing Technology 74 (1-4), 47-64.

Li, S., Wang, H., Hu, S. J., Lin, Y.-T., Abell, J. A., 2011. Automatic generation of assembly system configuration with equipment selection for automotive battery manufacturing. Journal of Manufacturing Systems 30 (4), 188-195.

Makssoud, F., Battaïa, O., Dolgui, A., 2014. An exact optimization approach for a transfer line reconfiguration problem. International Journal of Advanced Manufacturing Technology 72, 717-727.

Matta, A., Tomasella, M., Valente, A., 2007. Impact of ramp-up on the optimal capacity-related reconfiguration policy. International Journal of Flexible Manufacturing Systems 19, 173-194.

Mellichamp, J., Kwon, O.-J., Wahab, F., 1990. Fms designer: An expert system for flexible manufacturing system design. International Journal of Production Research 28 (11), 2013-2024.

Meyr, H., Wagner, M., Rohde, J., 2015. Structure of advanced planning systems. In: Supply chain management and advanced planning. Springer, pp. 99-106.

Michalos, G., Fysikopoulos, A., Makris, S., Mourtzis, D., Chryssolouris, G., 2015. Multi criteria assembly line design and configuration - an automotive case study. CIRP Journal of Manufacturing Science and Technology 9, 69-87.

Michalos, G., Makris, S., Mourtzis, D., 2012. An intelligent search algorithm-based method to derive assembly line design alternatives. International Journal of Computer Integrated Manufacturing 25 (3), 211-229.

Nazarian, E., Ko, J., Wang, H., 2010. Design of multi-product manufacturing lines with the consideration of product change dependent inter-task times, reduced changeover and machine flexibility. Journal of Manufacturing Systems 29 (1), 35-46.

Oesterle, J., Amodeo, L., 2014. Efficient multi-objective optimization method for the mixed-model-line assembly line design problem. Procedia CIRP 17, 82-87.

Papaioannou, G., Wilson, J., 2010. The evolution of cell formation problem methodologies based on recent studies (1997-2008): Review and directions for future research. European Journal of Operational Research 206 (3), 509-521.

Papakostas, N., Pintzos, G., Giannoulis, C., Nikolakis, N., G., C.,
2014. Multi-criteria assembly line design under demand uncertainty. Procedia CIRP 25, 86-92.

Pochet, Y., Wolsey, L. A., 2006. Production planning by mixed integer programming. Springer Science \& Business Media.

Safaei, N., Tavakkoli-Moghaddam, R., 2009. Integrated multi-period cell formation and subcontracting production planning in dynamic cellular manufacturing systems. International Journal of Production Economics 120 (2), 301-314.

Selim, H., Askin, R., Vakharia, A., 1998. Cell formation in group technology: review, evaluation and directions for future research. Computers and Industrial Engineering 34 (1), 3-20.

Terkaj, W., Tolio, T., Valente, A., 2009a. Design of Flexible Production Systems. No. 1. Ch. Designing Manufacturing Flexibility in Dynamic Production Contexts, pp. 1-18.

Terkaj, W., Tolio, T., Valente, A., 2009b. Design of focused flexibility manufacturing systems (ffmss),. In: Tolio, T. (Ed.), Design of Flexible Production Systems. Springer, pp. 47-66.

Tolio, T., Ceglarek, D., ElMaraghy, H. A., Fischer, A., Hu, S. J., Laperriere, L., Newman, S. T., Váncza, J., 2010. Species - coevolution of products, processes and production systems. CIRP Annals-Manufacturing Technology 59 (2), 672-694.

Tolio, T., Urgo, M., 2013. Design of flexible transfer lines: A casebased reconfiguration cost assessment. Journal of Manufacturing Systems 32, 325-334.

Wiendahl, H.-P., ElMaraghy, H. A., Nyhuis, P., Zäh, M. F., Wiendahl, H.-H., Duffie, N., Brieke, M., 2007. Changeable manufacturingclassification, design and operation. CIRP Annals-Manufacturing Technology 56 (2), 783-809.

\section{Appendix}

\begin{tabular}{lrrr}
\hline Element & $\mathbf{x}-\operatorname{dim}[\mathbf{m m}]$ & $\mathbf{y}$-dim [mm] & Cost [€] \\
\hline OP1 (nut pressing) & 800 & 600 & 26,000 \\
OP2 (resistance) & 900 & 600 & 50,000 \\
OP3 (adhesive) & 4,000 & 2,000 & 48,000 \\
OP4 (riveting) & 1,700 & 6,500 & 49,000 \\
Input station & 2,400 & 2,400 & 45,000 \\
Output station & 5,000 & 2,000 & 14,000 \\
Control unit & 500 & 3,500 & 120,000 \\
7-axis robot & Related to cell dimensions & 1,200 & 70,000 \\
Module & 1,200 & 1,200 & 10,000 \\
OP1 tools & - & - & 15,000 \\
OP2 tools & - & - & 12,000 \\
OP3 tools & - & - & 10,000 \\
OP4 tools & - & - & 8,000 \\
\hline
\end{tabular}

Table 5: Description of equipment components in terms of $2 D$ sizes and purchasing costs. 


\begin{tabular}{|c|c|c|c|c|c|}
\hline Op\# & FAG & Product 1 & Product 2 & Product 3 & $\overline{\text { Product } 4}$ \\
\hline Op1: & $\begin{array}{l}\text { Nut } \\
\text { pressing }\end{array}$ & $\mathrm{T} 1,12 s$ & - & $\begin{array}{l}\mathrm{T} 1,15 s ; \\
\mathrm{T} 2,20 s\end{array}$ & $\mathrm{~T} 1,30 s$ \\
\hline Op2: & $\begin{array}{l}\text { Resistance } \\
\text { joining }\end{array}$ & $\mathrm{T} 1,100 s$ & $\mathrm{~T} 1,200 s$ & $\mathrm{~T} 1,180 \mathrm{~s}$ & $\mathrm{~T} 2,210 s$ \\
\hline Op3: & $\begin{array}{l}\text { Adhesive } \\
\text { joining }\end{array}$ & $\mathrm{T} 2,15 s$ & $\begin{array}{l}\mathrm{T} 1,20 s \\
\mathrm{~T} 2,30 \mathrm{~s}\end{array}$ & - & - \\
\hline Op4: & $\begin{array}{l}\text { Riveting } \\
\text { joining }\end{array}$ & $\mathrm{T} 1,18 s$ & $\mathrm{~T} 2,20 s$ & - & - \\
\hline \multicolumn{6}{|c|}{ Total demand } \\
\hline \multirow[t]{3}{*}{ Case: } & Highest & 700 & 350 & 3,750 & 1,400 \\
\hline & Average & 650 & 200 & 2,400 & 750 \\
\hline & Lowest & 600 & 150 & 1,700 & 250 \\
\hline \multicolumn{6}{|c|}{ Scenario nodes } \\
\hline \multirow[b]{2}{*}{$\omega_{0}$} & demand & 500 & - & 600 & - \\
\hline & lot size & 40 & - & 30 & - \\
\hline \multirow[b]{2}{*}{$\omega_{1 A}\left(\omega_{0}\right)$} & demand & - & - & 1,800 & 900 \\
\hline & lot size & - & - & 30 & 35 \\
\hline \multirow{2}{*}{$\omega_{1 B}\left(\omega_{0}\right)$} & demand & - & - & 800 & 500 \\
\hline & lot size & - & - & 30 & 35 \\
\hline \multirow{2}{*}{$\omega_{1 C}\left(\omega_{0}\right)$} & demand & - & - & 300 & 100 \\
\hline & lot size & - & - & 30 & 35 \\
\hline \multirow{2}{*}{$\omega_{2 A}\left(\omega_{1 A}\right)$} & demand & 200 & 350 & 1,350 & 500 \\
\hline & lot size & 35 & 40 & 35 & 35 \\
\hline \multirow{2}{*}{$\omega_{2 B}\left(\omega_{1 A}\right)$} & demand & 150 & 300 & 1,100 & 400 \\
\hline & lot size & 35 & 40 & 35 & 35 \\
\hline \multirow{2}{*}{$\omega_{2 C}\left(\omega_{1 B}\right)$} & demand & 100 & 200 & 1,000 & 250 \\
\hline & lot size & 35 & 40 & 35 & 35 \\
\hline \multirow{2}{*}{$\omega_{2 D}\left(\omega_{1 A}\right)$} & demand & 115 & 200 & 900 & 240 \\
\hline & lot size & 35 & 40 & 35 & 35 \\
\hline \multirow{2}{*}{$\omega_{2 E}\left(\omega_{1 C}\right)$} & demand & 100 & 200 & 850 & 200 \\
\hline & lot size & 35 & 40 & 35 & 35 \\
\hline \multirow{2}{*}{$\omega_{2 F}\left(\omega_{1 C}\right)$} & demand & 100 & 150 & 800 & 150 \\
\hline & lot size & 35 & 40 & 35 & 35 \\
\hline
\end{tabular}

Table 6: Product information used as input for the tools: processing information for each product, including required tool (T\#) and processing time (upper part). Demand cases used as input for the Assembly System Configuration tool (middle part). Demand and lot sizes for each scenario node, where the notation $s_{1}\left(s_{0}\right)$ means that the scenario $s_{0}$ is the upstream father of scenario $s_{1}$ in the scenario tree. (lower part).

\begin{tabular}{lrr}
\hline \multirow{2}{*}{ Product type } & \multicolumn{2}{c}{ Layout alternatives } \\
& Layout $A$ & \multicolumn{1}{c}{ Layout $B$} \\
\hline Product 1 & 0.001237 & 0.000736 \\
Product 3 & 0.001543 & 0.000883 \\
Batch time & $224.74 h$ & $384.86 h$ \\
\hline Investment (FAG) & $422,000 €$ & $381,000 €$ \\
Investment (molds) & $50,000 €$ & $50,000 €$ \\
Investment (tools) & $60,000 €$ & $51,000 €$ \\
Operational cost & $11,237,000 €$ & $19,243 €$ \\
Total & $543,237 €$ & $501,243 €$ \\
\hline
\end{tabular}

Table 7: Comparison in terms of performances and costs between different layouts considering execution modalities 1 and 4 .

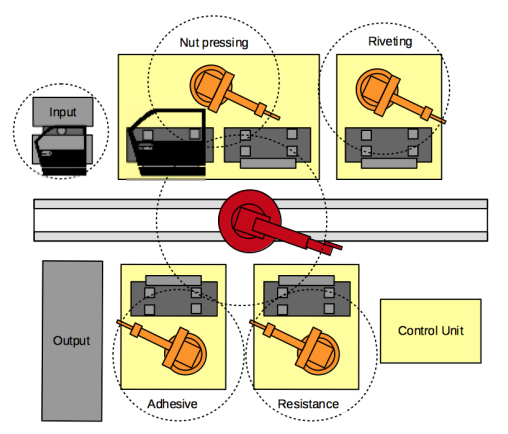

(a) Solution that considers all the assembly operations implemented with execution modality number 1 .

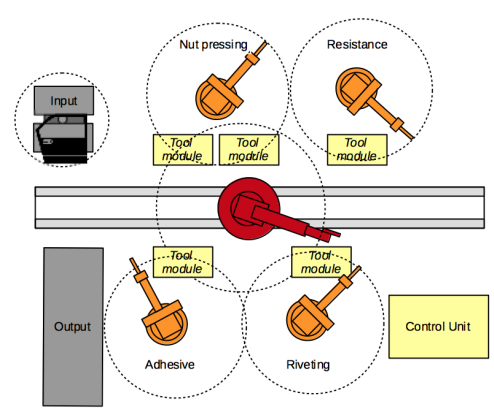

(b) Solution that considers all the assembly operations implemented with execution modality number 4.

Figure 5: Two possible solutions for the same problem: candidate layouts are able to satisfy market requests by considering alternative execution modalities.

\begin{tabular}{|c|c|c|c|c|c|c|}
\hline Period & KPI & Ideal & Contractual & Sc 1 & Sc 2 & Sc 3 \\
\hline \multirow{5}{*}{$t_{0}$} & Operational cost & 10,863 & 13,714 & 14,030 & 16,028 & 17,184 \\
\hline & Batch_P1 & 40 & 124 & 42 & 42 & 33 \\
\hline & Batch P2 & 0 & 0 & 0 & 0 & 0 \\
\hline & Batch P3 & 30 & 50 & 40 & 30 & 30 \\
\hline & Batch P4 & 0 & 0 & 0 & 0 & 0 \\
\hline \multirow{5}{*}{$t_{1}$} & Operational cost & 11,478 & 15,456 & 16,627 & 18,663 & 20,677 \\
\hline & Batch_P1 & 0 & 0 & 0 & 0 & 0 \\
\hline & Batch P2 & 0 & 0 & 0 & 0 & 0 \\
\hline & Batch P3 & 30 & 53 & 53 & 40 & 40 \\
\hline & Batch P4 & 35 & 42 & 33 & 33 & 25 \\
\hline \multirow{5}{*}{$t_{2}$} & Operational cost & 14,637 & 17,779 & 19,406 & 22,452 & 21,772 \\
\hline & Batch_P1 & 35 & 127 & 124 & 124 & 124 \\
\hline & Batch P2 & 40 & 47 & 40 & 33 & 27 \\
\hline & Batch P3 & 35 & 50 & 50 & 33 & 33 \\
\hline & Batch P4 & 35 & 42 & 33 & 33 & 33 \\
\hline
\end{tabular}

Table 8: Feedback on the resulted operation costs and batch sizes, provided by the Production Planning and Simulation tool. The Ideal includes the costs and batch sizes considered by the previous tools, whereas Contractual refines these costs. Scenarios Sc 1-3 assume that contractual delivery volume might change in the future resulting in more frequent deliveries. 